OPEN ACCESS

Edited by:

Biao Zhao,

Zhengzhou University of Aeronautics,

China

Reviewed by:

Ying Huang,

Northwestern Polytechnical University,

China

Isabelle Huynen,

Catholic University of Louvain,

Belgium

Yujin Chen,

Harbin Engineering University, China

*Correspondence:

Long Xia

xialonghit@gmail.com

Xiao Xiao Huang

swliza@hit.edu.cn

Specialty section:

This article was submitted to

Polymeric and Composite Materials,

a section of the journal

Frontiers in Materials

Received: 20 February 2020 Accepted: 07 April 2020

Published: 12 May 2020

Citation:

Li TT, Xia L, Zhang T, Zhong B,

Dai J, Tian X, Huang XX and Wen G (2020) Facile Synthesis

of Sn/Reduced Graphene Oxide

Composites With Tunable Dielectric

Performance Toward Enhanced

Microwave Absorption.

Front. Mater. 7:108

doi: 10.3389/fmats.2020.00108

\section{Facile Synthesis of Sn/Reduced Graphene Oxide Composites With Tunable Dielectric Performance Toward Enhanced Microwave Absorption}

\author{
Tian Tian Li ${ }^{1}$, Long Xia ${ }^{2 *}$, Tao Zhang ${ }^{2}$, Bo Zhong ${ }^{2}$, Jianghao Dai , Xiao Tian², \\ Xiao Xiao Huang ${ }^{1 *}$ and Guangwu Wen ${ }^{3}$
}

\begin{abstract}
${ }^{1}$ School of Materials Science and Engineering, Harbin Institute of Technology, Harbin, China, ${ }^{2}$ School of Materials Science and Engineering, Harbin Institute of Technology, Weihai, China, ${ }^{3}$ School of Materials Science and Engineering, Shandong University of Technology, Zibo, China
\end{abstract}

Electromagnetic (EM) wave absorbing materials are strongly desired for the reason that EM pollution has become a serious problem with the rapid development of modern technology, which brings harm to the environment and human health. Herein, nanocomposites of $\mathrm{Sn} /$ reduced graphene oxide (Sn/rGO) as a novel type of EM absorbing materials were synthesized via a facile and efficient strategy. Nanoscale $\mathrm{SnO}_{2}$ microspheres were synthesized by sol-gel method, and the Sn/rGO composites were obtained after hydrothermal process with GO. Samples with different Sn content were fabricated (rGO:Sn = 30:1, 20:1, 10:1, mass ratio), and their EM wave absorption performance were analyzed. By changing the mass ratio of Sn and $\mathrm{rGO}$, dielectric constant of the composites can be adjusted, and better impedance matching can be achieved. The unique capacitive structure and conductive network enable the material to have strong dielectric loss and excellent absorption performance. This research offers a new route for designing and fabricating high-frequency EM wave absorbing materials.

Keywords: new route, nanocomposites of $\mathrm{Sn} / \mathrm{rGO}$, tunable dielectric performance, high frequency absorption, excellent absorption performance

\section{INTRODUCTION}

With the rapid development of technology, electromagnetic (EM) interference has become a serious problem (Cao et al., 2018; Jia et al., 2018; Wei et al., 2018b; Wu G. et al., 2018; Lu S. et al., 2019), which not only causes damage to the operation of electronic devices, but also has a remarkable negative effect on human health (Liang et al., 2016, 2018; Oraizi et al., 2016; Smitha et al., 2016; Tian et al., 2017; Meng et al., 2018). The key to solve this problem relies on the development and application of EM wave absorbing materials (Batrakov et al., 2016; Liu T. et al., 2016). According to the loss mechanism, EM wave absorbing materials can be divided into dielectric materials and magnetic materials (Liu P. et al., 2018; Pang et al., 2018; Yang et al., 2018). However, magnetic materials will lose their magnetism at high temperature and thus cannot meet the application requirement in thermal environment. Therefore, a large number of researches and 
theories have been focused on designing dielectric materials with thin thickness, lightweight, wide absorption frequency range and strong absorption property (Liu et al., 2016; Liu P. et al., 2016; Song L. et al., 2017; Liu J. et al., 2018; Samadi et al., 2018; Wu F. et al., 2018; Xie et al., 2018; Liu et al., 2020).

Dielectric materials, such as carbon fibers (Shah et al., 2015), carbon coils (Hu et al., 2018), carbon nanotubes (Makarova et al., 2016), carbon black (Al-Ghamdi et al., 2016), are mainly carbon materials due to low density, high dielectric loss and adjustable surface properties (Guan et al., 2017; Xu et al., 2017; Wang S.S. et al., 2018; Wei et al., 2018a; Zhang L. et al., 2018; Wu et al., 2019), and a lot of researches have been conducted on them. Sun et al. synthesized a vertically arranged carbon nanotube array by means of chemical vapor deposition. Carbon nanotube has a multi-wall structure, with an average diameter of $11 \mathrm{~nm}$ and light weight. By changing the stacking angle, the absorption frequency can be precisely controlled to increase the microwave absorption intensity of CNTs. When the superposition angle between two adjacent carbon nanotubes is $90^{\circ}$, the best absorption performance is obtained, and the reflection loss reaches $-47.66 \mathrm{~dB}$ (Sun et al., 2014). Chen et al. prepared a multiwall carbon nanotube (MWCNT)/graphene foam (GFs) composites (CGFs) with high efficiency microwave absorption using a simple solvent-thermal method. By changing MWCNT load and thermal reduction temperature, complex permittivity and conductivity of CGFs can be adjusted effectively. The introduction of MWCNT improves the EM wave absorption property of CGFs at low frequency and has the widest effective bandwidth of $16 \mathrm{GHz}$ (Chen et al., 2017). Although carbon materials have good absorbing performance, light weight and wide effective frequency band at low frequency, they cannot meet the application requirement in harsh thermal environment.

Carbon materials can be compounded with other materials (metal, metal oxide, high transmittance material) in order to obtain good EM wave absorbing property at high temperature, for example, $\mathrm{ZnO} @ M W C N T s, \mathrm{MnO}_{2} / \mathrm{RGO}, \mathrm{RGO} / \mathrm{ZnO} \mathrm{CeO}_{2}-\mathrm{RGO}$, $\mathrm{CoNi} / \mathrm{rGO}, \mathrm{Fe} /$ graphene, $\mathrm{Fe}_{3} \mathrm{O}_{4}$-Fe/G, FeNi@NC/NCNT/NrGO, G/CoNi@NCNTA, NiFe/N-GCT, $\mathrm{SiO}_{2} @ \mathrm{Fe}_{3} \mathrm{O}_{4} / \mathrm{G}$ and so on (Ren et al., 2013; Wen et al., 2013; Zhang et al., 2015, 2019a,b,c, 2020; Qu et al., 2016; Wang Z.Q. et al., 2018; Yan et al., 2018; Hu et al., 2019; Xu et al., 2020). Xia et al. focus on the synthesis of lithium aluminum silicate (LAS) glass-ceramic with high transmittance (>90\%; $1.7 \mathrm{~mm} ; 2$ $18 \mathrm{GHz}$ ) to electromagnetic wave. And then, the LAS/rGO nanocomposites with low density, broad band, and strong absorption was designed. The dielectric properties of the composites were adjusted by LAS transmittance material with ultra-low complex dielectric constant. As a result, LAS/rGO nanocomposites possess ultra-high EM wave absorbing property. However, there are many deeper mechanisms to explore due to the elemental diversity of the LAS materials (Xia et al., 2018; $\mathrm{Lu}$ S. et al., 2019). Cao et al. synthesized $\mathrm{ZnO}$ nanocrystals modified multi-walled carbon nanotubes (ZnO@MWCNTS) by solution method. The addition of zinc oxide appropriately adjusts the complex dielectric constant, and this ultra-lightweight composite exhibits greater dielectric loss and high efficiency of EM wave absorption by generating additional interfacial interactions compared to physical mixing. A series of excellent properties of ZnO@MWCNTS indicate that it is a kind of absorbing material that can be used in high temperature environment (Wen et al., 2013). Wang et al. prepared $\mathrm{CeO}_{2}-\mathrm{rGO}$ composites with good EM wave absorption property by onestep hydrothermal method. When the mass ratio of $\mathrm{CeO}_{2}: \mathrm{GO}$ is $10: 1$, the synthesized composite has a minimum reflection loss $\mathrm{RL}$ of $-45.91 \mathrm{~dB}(2.0 \mathrm{~mm}, 13.28 \mathrm{GHz})$, which is 73.35 and 6.14 times better than $\mathrm{CeO}_{2}$ and RGO, respectively (Wang Z.Q. et al., 2018). Metal oxides can be introduced into carbon materials to adjust impedance matching and effectively improve the absorbing performance. However, a crucial issue for putting absorbing material into device application is to understand the physics of metal-carbon materials interface in the device. Hence, metal-carbon materials are studied in order to make more absorbents into devices. Zhao et al. synthesized graphene-coated $\mathrm{Fe}(\mathrm{Fe} / \mathrm{G})$ nanocomposites for the first time and investigated their EM wave absorption properties. Due to the charge transfer at Fe-graphene interface in $\mathrm{Fe} / \mathrm{G}$, the nanocomposites show distinct dielectric properties, which result in excellent EM wave absorption performance in a wide frequency range. The minimum $\mathrm{RL}$ is about $-45 \mathrm{~dB}$ at $7.1 \mathrm{GHz}(3 \mathrm{~mm})$. It provides a novel approach for exploring high-performance EM wave absorption material (Zhao et al., 2013). Therefore, it can be predicted that this mode has a good development prospect in the field of EM wave absorption, which chooses the non-magnetic metal with quite different conductivity from carbon materials for synthesis to regulate EM wave absorption property of composites.

Herein, we reported a facile and effective strategy to fabricate $\mathrm{Sn} / \mathrm{rGO}$ composites. Sn microspheres were successfully coated by rGO via a one-step hydrothermal method. The microstructure and EM wave absorption property were investigated. Sn, with a low conductivity, was introduced to adjust the dielectric loss of the composites. The dielectric constant and impedance matching of composites were adjusted by controlling the ratio of samples mass. The result indicated that the improved properties of $\mathrm{Sn} / \mathrm{rGO}$ composites can be attributed to their unique architecture and the conductivity differences between $\mathrm{Sn}$ microspheres and rGO. This work aimed to explore a facile method to compound dielectric materials with adjustable dielectric properties.

\section{EXPERIMENTAL SECTION}

\section{Materials}

Tin (II) chloride dihydrate $\left(\mathrm{SnCl}_{2} \cdot 2 \mathrm{H}_{2} \mathrm{O}\right.$, A.R.) was purchased from Xilong Chemical Research Institute in China. Tetraethyl silicate (TEOS, A.R.), N-Hexane (A.R.) and Sodium hydroxide $(\mathrm{NaOH}$, A.R.) were provided by Beijing Chemical Works Research Institute in China. 3-aminopropyltriethoxysilane $\left[\mathrm{NH}_{2}\left(\mathrm{CH}_{2}\right)_{3} \mathrm{Si}\left(\mathrm{OC}_{2} \mathrm{H}_{5}\right)_{3}, \mathrm{KH}-550\right]$ was obtained from Jinan Jinhui Chemical co. LTD. Graphene oxide (GO) dispersed solution (0.94 wt\%) was purchased from Changzhou Sixth Element Material Technology co. LTD. All the chemical reagents 
were analytical grade and used without further purification. Ethanol and deionized water were used for all process of washing and dissolution.

\section{Preparation of Nanoscale $\mathrm{SnO}_{2}$ Microspheres}

$0.05 \mathrm{~mol} \mathrm{SnCl} 2 \cdot 2 \mathrm{H}_{2} \mathrm{O}$ was dissolved in $6.2 \mathrm{~mL}$ anhydrous ethanol and $3.8 \mathrm{~mL}$ deionized water, and then stirred for $2-3 \mathrm{~h}$ to obtain uniform mixed solution at room temperature. After that, $5.7 \mathrm{~mL}$ tetraethyl silicate (TEOS) was added into the solution slowly and formed gel. The sample was aged for $24 \mathrm{~h}$ at room temperature, and then was aged for 2 days under $70^{\circ} \mathrm{C}$. The obtained gel was soaked in $n$-hexane for 2 days under $50^{\circ} \mathrm{C}$ to replace solvent. The product was soaked in $\mathrm{NaOH}$ solution $(2 \mathrm{~mol} / \mathrm{L})$, stirred for $30 \mathrm{~min}$ under $50^{\circ} \mathrm{C}$. Finally, the solution was filtered, washed, dried and calcined at $550^{\circ} \mathrm{C}$, and so the expected nanoscale $\mathrm{SnO}_{2}$ microspheres were obtained.

\section{Fabrication of Sn/rGO Composites}

GO dispersed solution and $50 \mathrm{~mL}$ deionized water were mixed by ultrasonic for $2 \mathrm{~h}$, previously prepared nanoscale $\mathrm{SnO}_{2}$ microspheres and $1 \mathrm{~mL} \mathrm{KH-550} \mathrm{were} \mathrm{added} \mathrm{into} \mathrm{the} \mathrm{mixture,}$ and stirred for $30 \mathrm{~min}$. Then, the mixture was treated using hydrothermal method at $180^{\circ} \mathrm{C}$ for $12 \mathrm{~h}$, After freeze drying, the powder was sintered at $800^{\circ} \mathrm{C}$ for $2 \mathrm{~h}$ (under Ar atmosphere). Finally, Sn/rGO composites were obtained. The schematic illustration of $\mathrm{Sn} / \mathrm{rGO}$ composites is shown in Figure 1. Samples with different mass ratio of 10:1, 20:1 and 30:1 (GO: Sn) were named A1, A2, and A3, respectively. Pure rGO without Sn was used for comparison.

\section{Characterization}

The phase structure and crystalline component of the composites were analyzed using X-ray diffraction (XRD, DX-2700, with highintensity $\mathrm{Cu}-\mathrm{K} \alpha$ radiation source). Raman spectra were acquired at room temperature by using a $532 \mathrm{~nm}$ laser (Renishaw, RM1000). The morphology and microstructure of the composites were investigated by field emission scanning electron microscopy (SEM, MERLIN Compact) and transmission electron microscopy (TEM, JEOL-2100) with energy dispersive $\mathrm{x}$-ray analysis (EDAX). The complex permittivity and complex permeability values in the frequency range of $2-18 \mathrm{GHz}$ were obtained with a vector network analyzer (VNA, Agilent N5245A, United States). Sample rings for electromagnetic measurement were prepared by uniformly mixing the composites into paraffin (Sn/rGO: $5 \mathrm{wt} \%$ ) and pressed into a ring mold with an outer diameter of $7 \mathrm{~mm}$ and inner diameter of $3 \mathrm{~mm}$. The transmission line theory was applied to calculate the reflection loss (RL) so as to analyze the EM wave absorption property.

\section{RESULTS AND DISCUSSION}

\section{Structural Analysis}

Crystal phases of the samples were analyzed by XRD. XRD patterns of $\mathrm{SnO}_{2}, \mathrm{rGO}, \mathrm{A} 1$ (10:1), $\mathrm{A} 2$ (20:1) and A3 (30:1) are given in Figure 2. It is clear that rGO has a broad weak characteristic peak at around $2 \theta=22.3^{\circ}$, which can be assigned to the (002) crystal planes (Quan et al., 2017a; Xu et al., 2018). A1, A2, and A3 samples all maintain the same characteristic peak. With the increase of GO content, the characteristic peak becomes more obvious and higher. Meanwhile, the peaks at $2 \theta=26.6^{\circ}, 33.8^{\circ}$ and $51.8^{\circ}$ correspond to (110), (101) and (211) plane of $\mathrm{SnO}_{2}$ (JCPDS no.46-1088), where the interlayer spacing of (110) plane is approximately $0.33 \mathrm{~nm}$. The interlayer spacing is calculated using Bragg equation (Feng, 2016; Li et al., 2018; Zhang N. et al., 2018), which is expressed as $d=\lambda / 2 \sin \theta=26.6^{\circ}$ (Li et al., 2018). The characteristic peak of Sn can be found in $\mathrm{A} 1, \mathrm{~A} 2$, and $\mathrm{A} 3$, located at $2 \theta=30.644,32.018,43.871$, $44.902,55.330,62.538,64.576,72.414$, and 79.470 corresponding to the (200), (101), (220), (211), (301), (112), (321), (420), and (312) planes, respectively. And the width of the peak is narrower than that of $\mathrm{SnO}_{2}$, indicating better crystallinity. In addition, the position of the peak has changed, which can be caused by the reduction of $\mathrm{SnO}_{2}$ during calcination. This is further confirmed that the generation of new grains in Figures 4B-D. The majority of the XRD pattern of the $\mathrm{Sn} / \mathrm{rGO}$ hybrids is found to be very similar. However, there is a slight shift in the position of the diffraction peaks, indicating that $\mathrm{Sn}$ is successfully anchored onto the rGO sheet and forms some interactions (Wang Z.Q. et al., 2018). As a result, chemical binding occurs between Sn and rGO because simple loads cannot cause peak offset. Among them, the KH-550 plays an important role in this process. It can enhance the interface bonding force between Sn and rGO, so that more $\mathrm{Sn}$ microspheres can grow on the $\mathrm{rGO}$ sheet (Lu S. et al., 2019). All the evidence points to the composites being synthesized.

The ordered degree of carbon material was distinguished by Raman spectroscopy. Figure 3 depicts the Raman spectra of $\mathrm{rGO}, \mathrm{A} 1, \mathrm{~A} 2$, and $\mathrm{A} 3$. Two prominent peaks of $\mathrm{D}$ and $\mathrm{G}$ are observed, which are around 1,330 and $1,580 \mathrm{~cm}^{-1}$, respectively. It is obvious that there is a trend of the intensity ratio of $\mathrm{D}$ band to $\mathrm{G}$ band $\left(\mathrm{I}_{\mathrm{D}} / \mathrm{I}_{\mathrm{G}}\right)$ for the samples (A3 > A2 > A1 > rGO) (Lin et al., 2015; Kumar et al., 2016; Zhang et al., 2016; Huang et al., 2017). As the content of Sn increases, the disordered and defect degree of the composites decreases, indicating the separation of rGO layers after fastening of $\mathrm{Sn}$ on rGO sheets and further restoration of the sp (Wu G. et al., 2018) network of rGO (It is consistent with the morphology of SEM and XRD results) (Liu J. et al., 2018; Wang Z.Q. et al., 2018). Notably, the slight blue shift of Raman peaks for the composites compared with rGO, which indicates $\mathrm{Sn}$ microspheres were successfully covered by rGO (Shu et al., 2018). And there is a charge interaction on multiple interfaces, which can improve the EM wave absorption property of the composites.

The morphologies of $\mathrm{SnO}_{2}$ and A2 (20:1) with different magnification are shown in Figure 4. A1, A2, and A3 have the same shape and appearance, only differ in the concentration of $\mathrm{Sn}$. In Figure 4a, $\mathrm{SnO}_{2}$ shows a loose porous structure, which is composed of many microspheres (diameter is $\sim 150 \mathrm{~nm}$ ) with rough surface. As can be seen from Figure $4 \mathbf{b}$, the reduced $\mathrm{Sn}$ microspheres are evenly distributed on the surface of rGO sheet. It's clear that the size of the microspheres has increased 


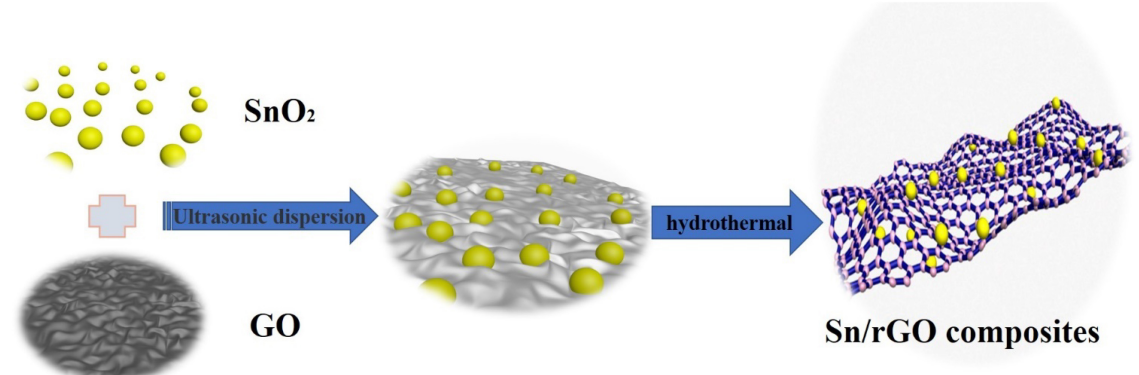

FIGURE 1 | Schematic illustration of the fabrication process for $\mathrm{Sn} / \mathrm{rGO}$ composites.

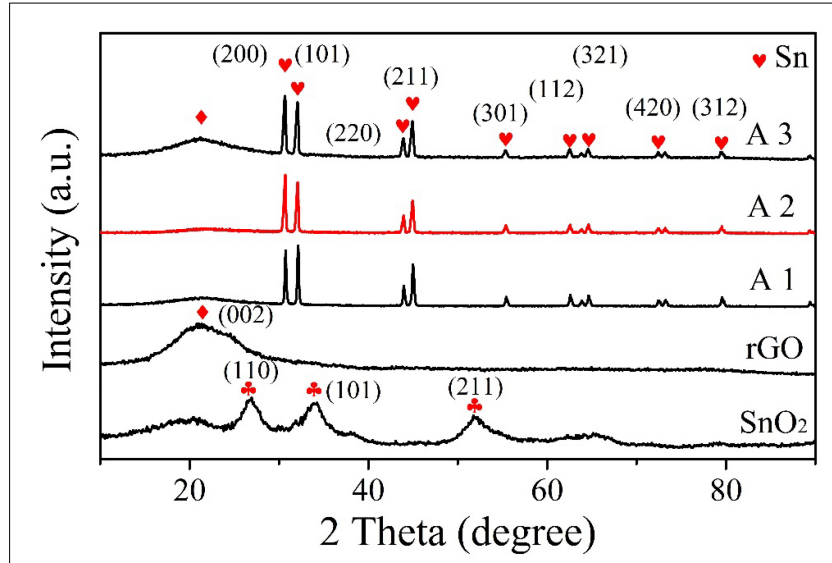

FIGURE 2 |XRD patterns of $\mathrm{SnO}_{2}, \mathrm{rGO}$, and $\mathrm{Sn} / \mathrm{rGO}$ composites with different mass ratio (GO:Sn) A1 (10:1), A2 (20:1), and $A 3$ (30:1), respectively.

(diameter is $\sim 1.50 \mu \mathrm{m}$ ), proving that $\mathrm{SnO}_{2}$ is reduced to $\mathrm{Sn}$ during hydrothermal process, which is consistent with the XRD results. Figures $\mathbf{4 c , d}$ exhibit that $\mathrm{Sn}$ is not only attached to the surface of rGO sheet, but also tightly wrapped in the slice layer of rGO. There are multiple interfaces between $\mathrm{Sn}$ and rGO sheet (marked by a red dotted circle), which has a positive effect on EM wave absorption performance.

The microstructure of the annealed composites was further investigated by TEM. The obtained lattice spacing is $0.33 \mathrm{~nm}$, which matches the (110) crystal planes of $\mathrm{SnO}_{2}$ microspheres in Figure 5a. As shown in Figures 5b,c, Sn solid microspheres evenly distribute on the surface of rGO slice layer. Figures $\mathbf{5 e -} \mathbf{g}$ are the energy spectra diagram of A2 corresponding to Figure 5d, which display the presence of the $\mathrm{C}, \mathrm{Sn}$, and $\mathrm{O}$ elements. These are consistent with SEM results.

\section{EM Wave Absorption Properties}

To investigate the EM wave absorption properties of $\mathrm{rGO}, \mathrm{A} 1$ (10:1), A2 (20:1) and A3 (30:1), the samples were mixed with wax (filler loading: $5 \mathrm{wt} \%$ ) to analyze the relative complex permittivity and permeability. The electromagnetic parameters are important for EM wave absorbing material. As a kind of dielectric loss materal, the composites hardly exhibit any magnetic loss, so it

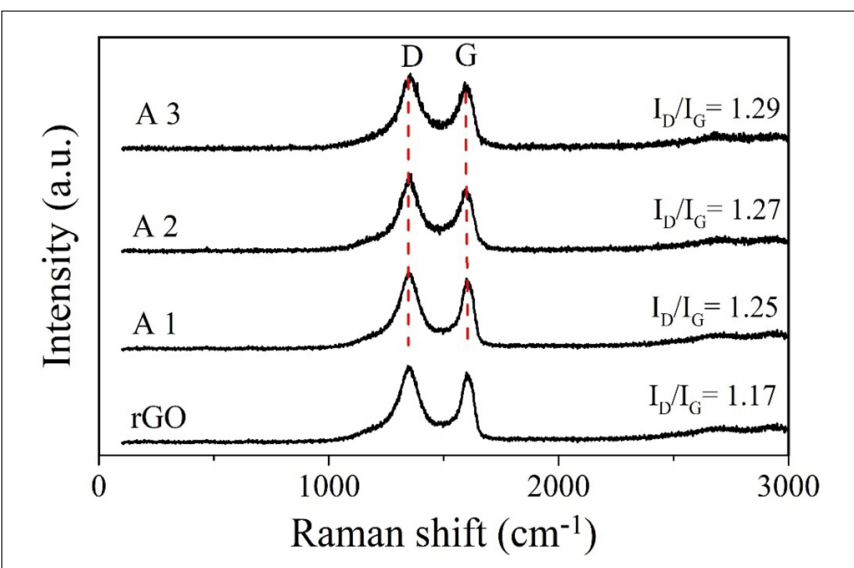

FIGURE 3 | Raman spectra of $\mathrm{rGO}, \mathrm{A} 1, \mathrm{~A} 2$, and A3.

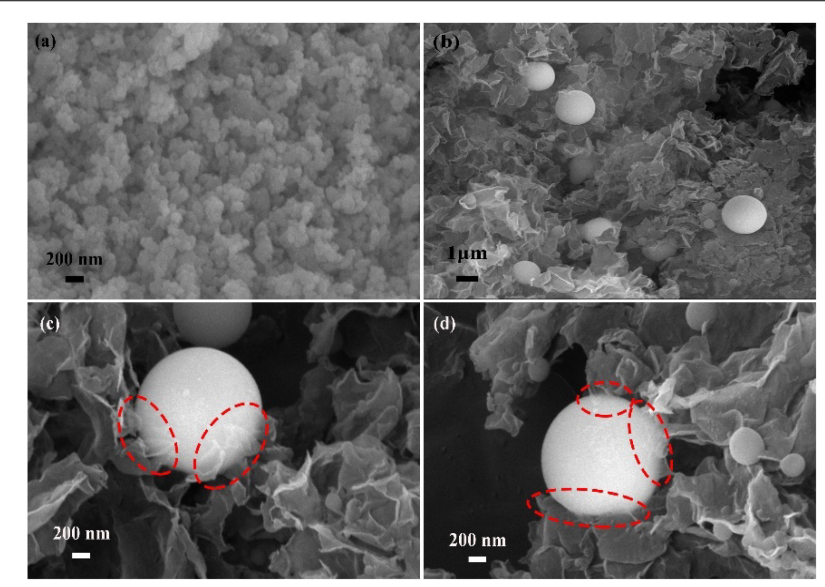

FIGURE 4 | SEM images of (a) $\mathrm{SnO}_{2}$, (b-d) A2 with different magnification.

can be ignored. In Figures 6C,D, the real part and imaginary part of permeability for all samples are around 1 and 0 , respectively. It can be noted from the magnetic loss tangent curve (Figure 6F) that the magnetic loss is almost 0 . The zigzag fluctuations in the first half of the figures, which indicates that $\mathrm{rGO}$ and $\mathrm{Sn} / \mathrm{rGO}$ composites are high dielectric material but weakly magnetic. The 

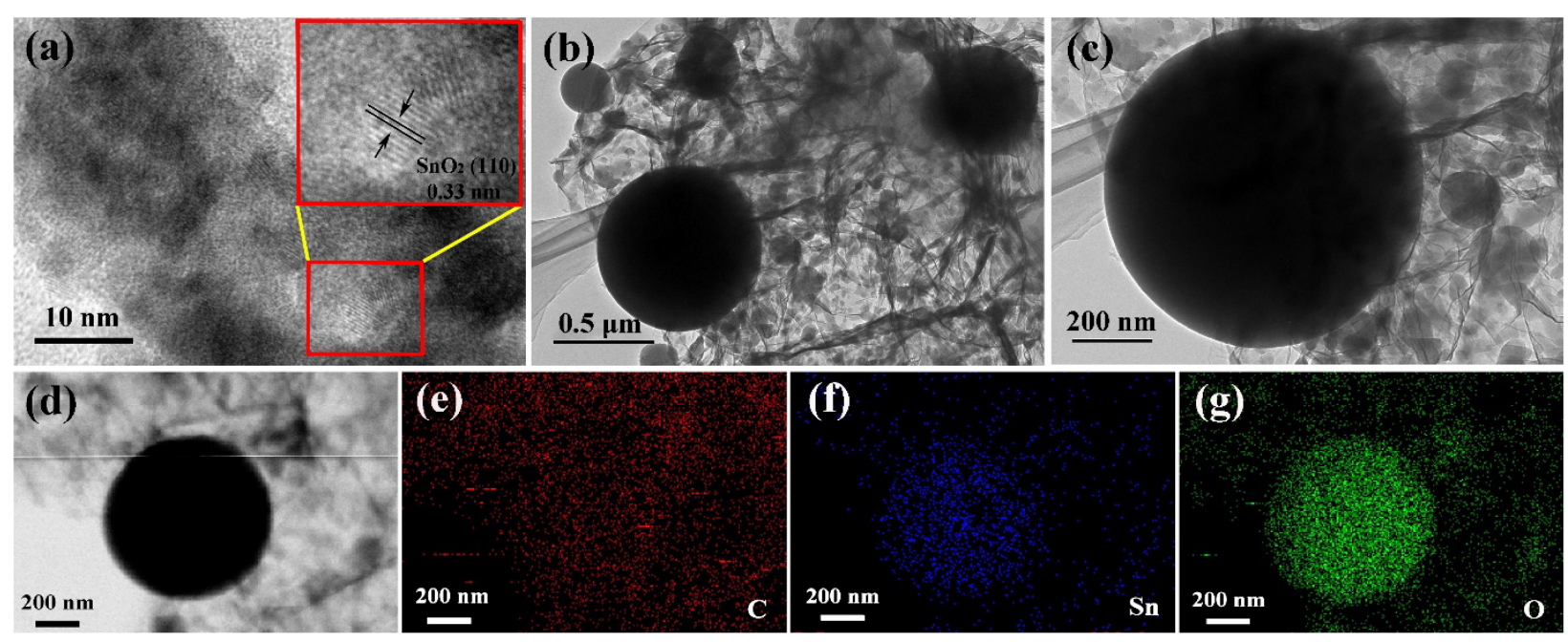

FIGURE 5 | (a) HRTEM image of $\mathrm{SnO}_{2}$, (b-d) TEM images of A2 and (e-g) energy spectra diagram of C, $\mathrm{Sn}$, and O elements corresponding to (d).

$\mu^{\prime}$ and $\mu^{\prime \prime}$ values of these samples have a small fluctuation in the $2-8 \mathrm{GHz}$ frequency range, which is caused by the small size effect, surface effect, and spin wave excitations (Wang Z.Q. et al., 2018). Moreover, these permeability values are typical for materials that have no magnetic properties, which fluctuates in the range of $1 \pm 0.2$ and $0 \pm 0.2$, respectively ( $\mathrm{Li}$ et al., 2018). The real part of permittivity represents energy storage capacity, and the imaginary part of permittivity can stand for energy dissipation, which can be expressed as follows according to Maxwell's equation and Debye theory (Zhang C. et al., 2017; Lu S.R. et al., 2019):

$$
\begin{gathered}
\varepsilon^{\prime}=\varepsilon_{\infty}+\frac{\varepsilon_{s}-\varepsilon_{\infty}}{1+\omega^{2} \tau^{2}} \\
\varepsilon^{\prime \prime}=\varepsilon_{p}^{\prime \prime}+\varepsilon_{c}^{\prime \prime}=\frac{\varepsilon_{s}-\varepsilon_{\infty}}{1+\omega^{2} \tau^{2}} \omega \tau+\frac{\sigma}{\omega \varepsilon_{0}}
\end{gathered}
$$

where $\varepsilon_{\infty}, \varepsilon_{0}$ and $\varepsilon_{s}$ are the permittivity at infinite frequency, dielectric constant of free space and the static frequency, respectively. $\varepsilon_{p}^{\prime \prime}$ and $\varepsilon_{c}^{\prime \prime}$ are the polarization loss and conductivity loss, respectively. $\omega$ is the angular frequency $(2 \pi f), \tau$ is the relaxation time of dipoles, $\sigma$ is the conductivity which can be calculated based on measured $\varepsilon^{\prime}$ and $\varepsilon^{\prime \prime}$. This work aims to adjust the dielectric constant based on conductivity, and focuses on the relationship between conductivity and the absorption property. In Figures 6A,B,E, We can see a clear curvilinear trend that $\mathrm{A} 2>\mathrm{A} 3>\mathrm{A} 1$ (besides $\mathrm{rGO}$ ) of $\varepsilon^{\prime}, \varepsilon^{\prime \prime}$ and tan $\delta_{\varepsilon}\left(\varepsilon^{\prime \prime} / \varepsilon^{\prime}\right)$ in 2-18 GHz. rGO shows the highest $\varepsilon^{\prime \prime}$ and tan $\delta_{\varepsilon}$, indicating that $\mathrm{rGO}$ has high dielectric loss capacity due to excellent conductivity. However, this can lead to high reflection at the absorber interface and poor impedance matching, resulting in low attenuation. In summary, the impedance matching of the composites can be adjusted by introducing Sn microspheres. A2 has the highest value of permittivity among the samples, demonstrating the best energy storage and dissipation capacity. The high complex permittivity of A2 can be ascribed to multiple interfacial polarizations between Sn and rGO. In a heterogeneous system, electric charge can accumulate at the interface of two phases with different dielectric constants, leading to interfacial polarization (Maxwell-Wagner polarization). Sn microspheres have low conductivity, when recombined with rGO, oxygen vacancies enhance the conductivity of local electrons. According to free-electron theory, increased conductivity of A2 can lead to strong dielectric loss. Dielectric loss capacity is strengthened due to the charge transfer interaction between $\mathrm{Sn}$ microspheres and rGO. In Figures 6E,F, it can be seen that the values of $\tan \delta \varepsilon$ are higher than those of $\tan \delta_{\mu}\left(\mu^{\prime \prime} / \mu^{\prime}\right)$, which proves that dielectric loss dominates in EM wave attenuation of the composites.

It is well-known that reflection loss (RL) value can be used to judge the EM wave absorption performance. Lower RL means more EM wave energy can be absorbed. According to the transmission line theory, the RL of the samples can be calculated by the following equations (Feng et al., 2016; Huang et al., 2017; Li et al., 2017; Song C.Q. et al., 2017; Zhang N. et al., 2017):

$$
\begin{gathered}
\mathrm{RL}=20 \lg \left|\frac{Z_{\text {in }}-1}{Z_{\text {in }}+1}\right| \\
Z_{\text {in }}=\sqrt{\frac{\mu_{r}}{\varepsilon_{r}}} \tan h\left(j \frac{2 \pi f d}{c} \sqrt{\mu_{r} \varepsilon_{r}}\right) \\
\varepsilon_{r}=\varepsilon^{\prime}-j \varepsilon^{\prime \prime} \quad \mu_{r}=\mu^{\prime}-j \mu^{\prime \prime}
\end{gathered}
$$

where $Z_{i n}, \mu_{r}, \varepsilon_{r}, f, d$, and $c$ are the normalized input impedance, the complex permeability, the complex relative permittivity, the EM wave frequency, the sample thickness and the EM wave velocity in vacuum.

Figure 7 shows the frequency dependence of reflection loss of $\mathrm{rGO}, \mathrm{A} 1, \mathrm{~A} 2$, and $\mathrm{A} 3$ with different thicknesses. The values of RL lower than $-10 \mathrm{~dB}$ correspond to $90 \%$ energy absorption. The RL curves of rGO (Figure 7A) show that the value of $\mathrm{RL}_{\text {min }}$ is $-21.49 \mathrm{~dB}$ with a thickness of $2.5 \mathrm{~mm}$ and a wide absorption 
A

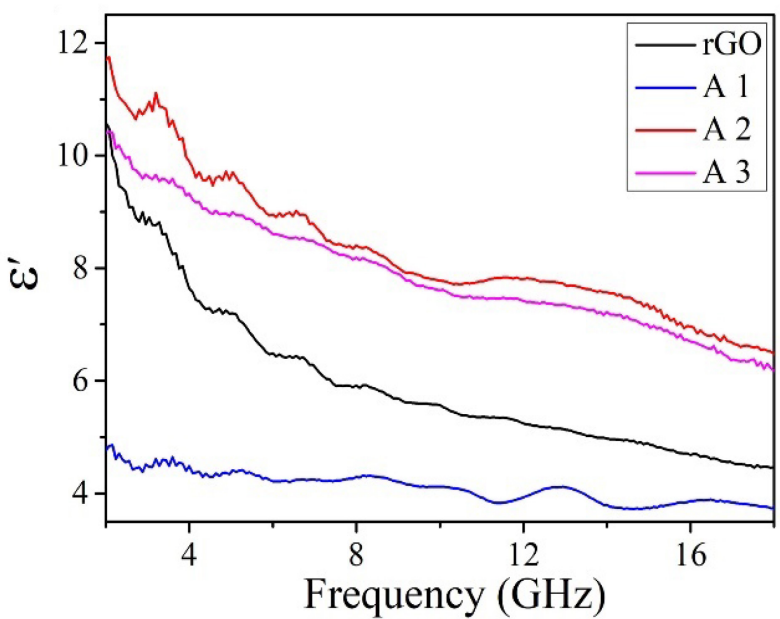

C

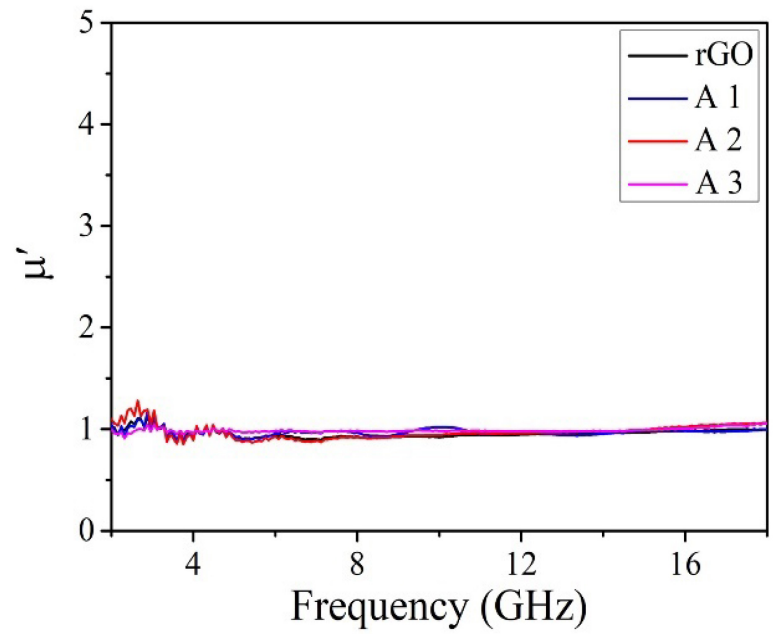

E

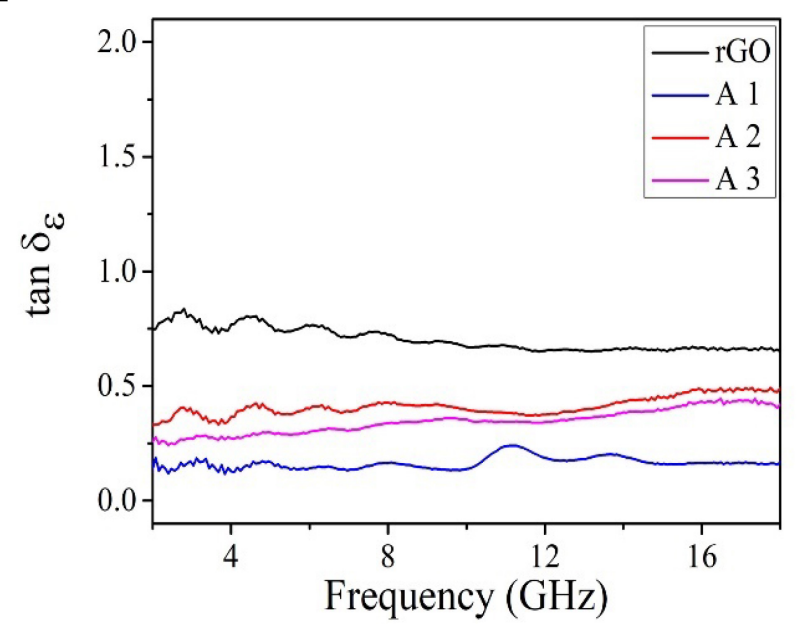

B

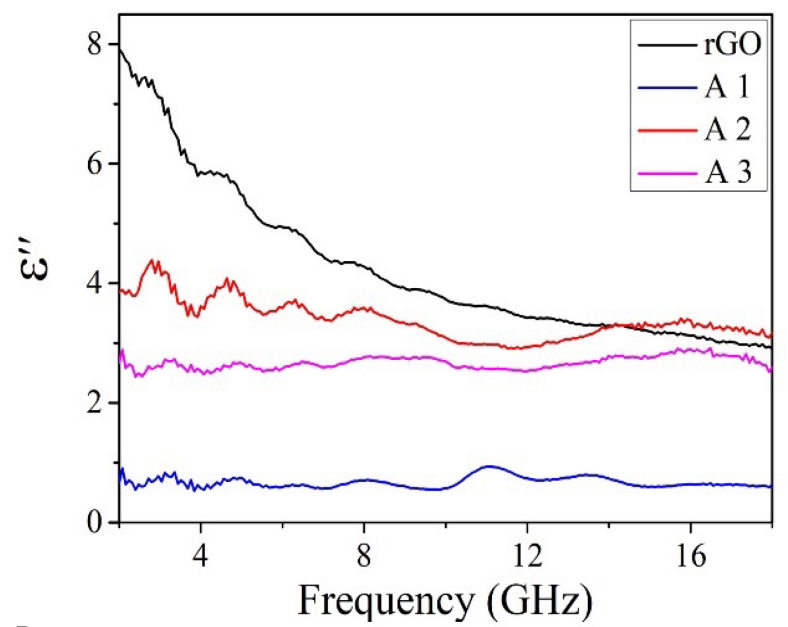

D

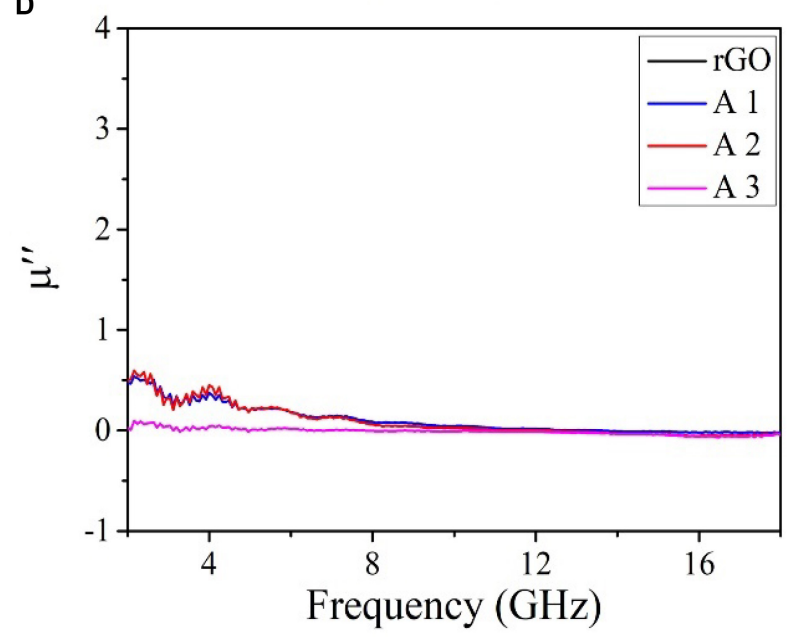

F

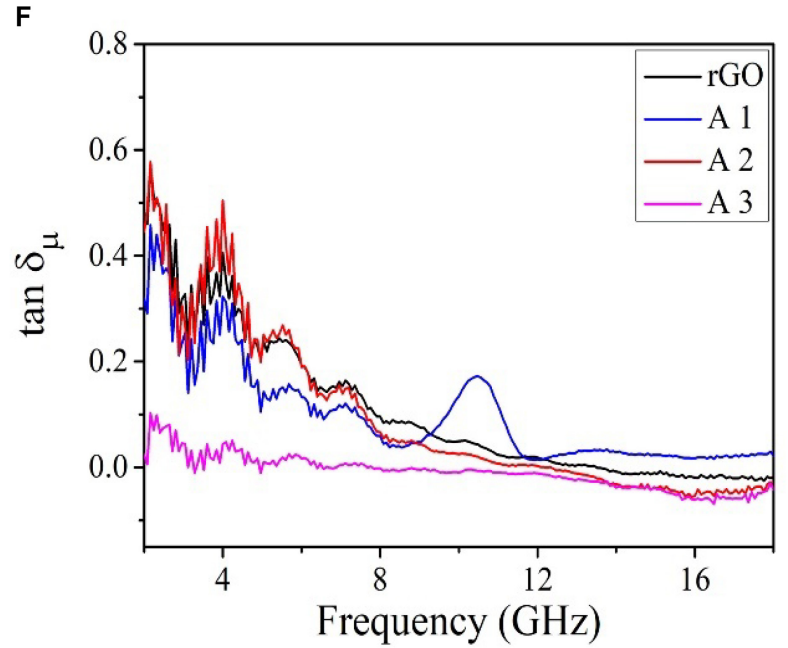

FIGURE 6 | (A) Permittivity real part, (B) permittivity imaginary part, (C) permeability real part, (D) permeability imaginary part, (E) dielectric loss tangent, (F) magnetic loss tangent of $r G O, A 1, A 2$, and $A 3$. 
A

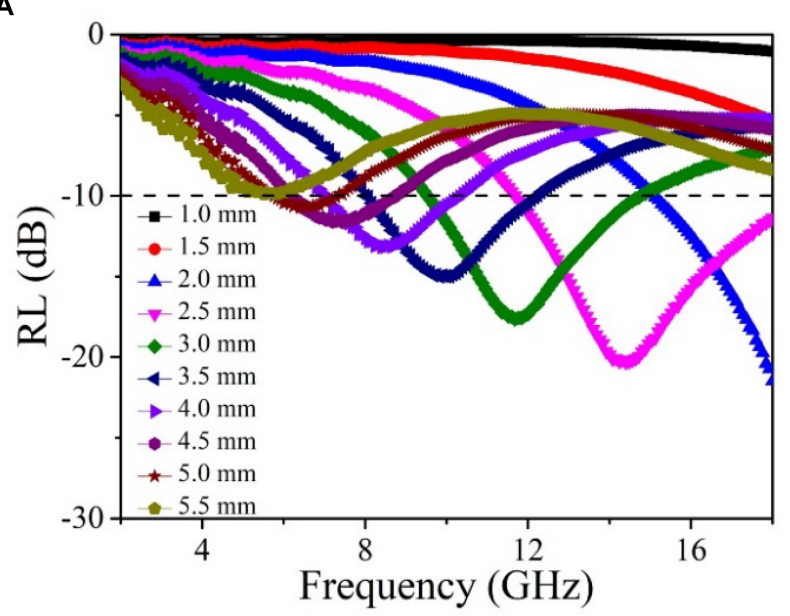

C

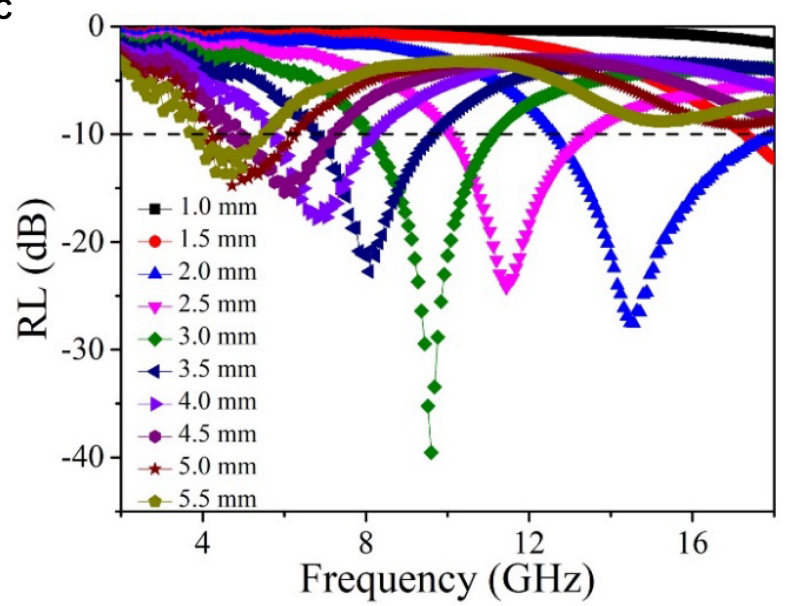

B

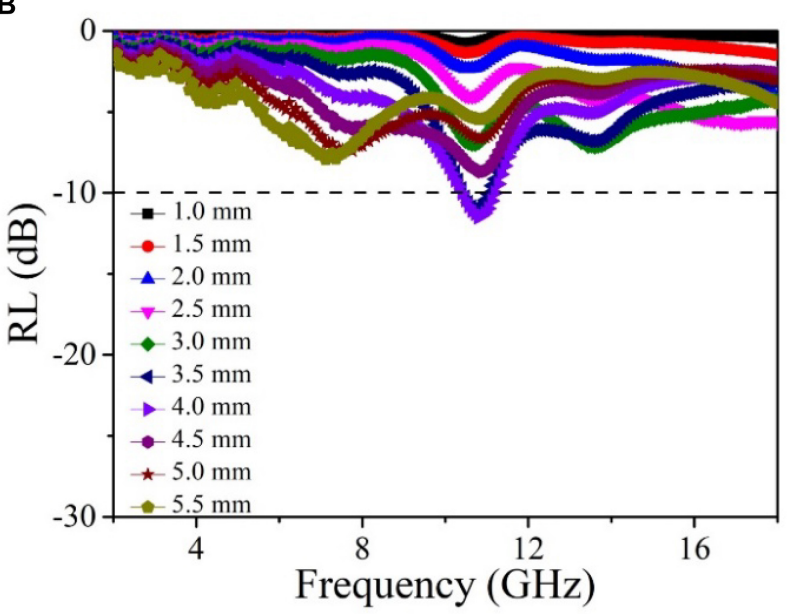

D

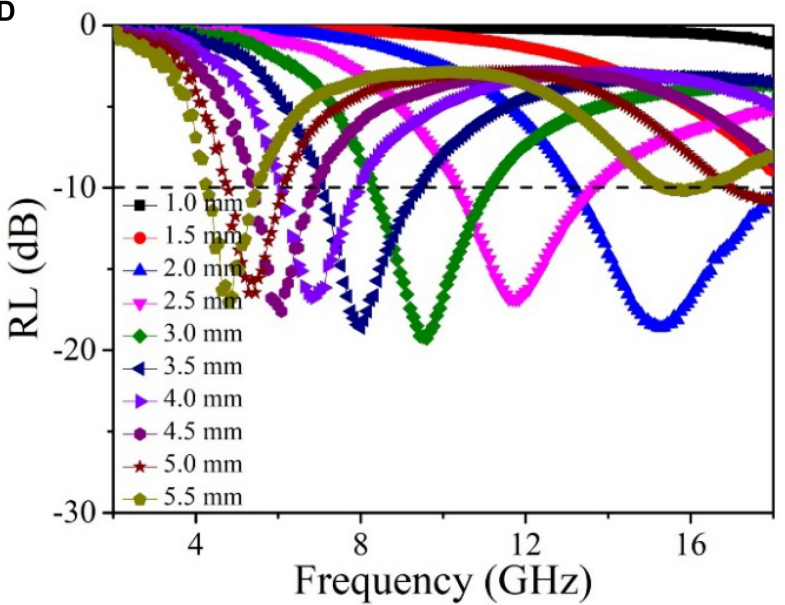

FIGURE 7 | Frequency dependence of reflection loss with different thicknesses in the frequency range of 2-18 GHz: (A) rGO, (B-D) A1, A2, and A3.

A

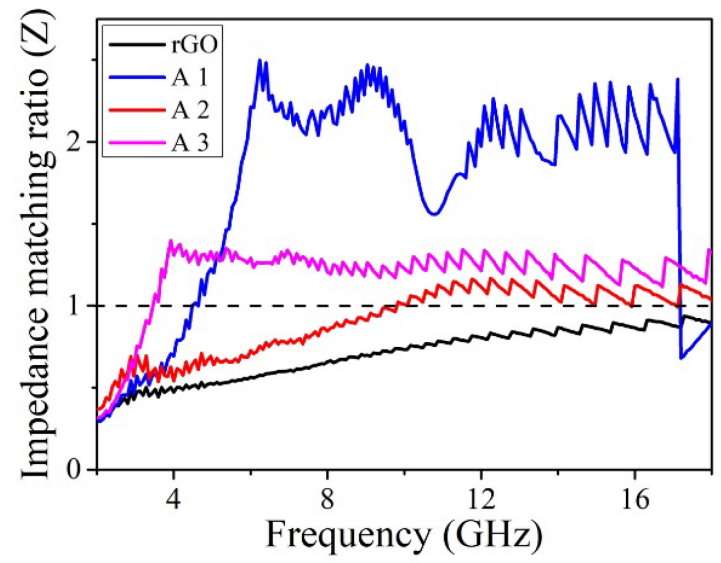

B

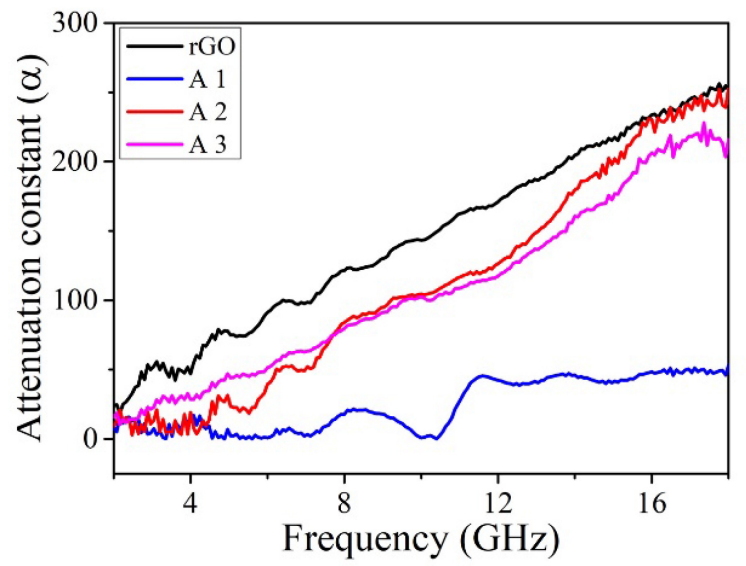

FIGURE 8 | Frequency dependence of (A) impedance matching ratio and (B) attenuation constant of rGO, A1, A2, and A3. 
TABLE 1 | The EM wave absorption performance of $r G O, A 1, A 2$, and A3 with the same filler loading (Sn/rGO: 5 wt\%).

\begin{tabular}{|c|c|c|c|c|c|}
\hline Material Sn/rGO composites & Frequency range (GHz) & Thickness (mm) & Maximum RL (dB) & $\mathrm{RL}<-10 \mathrm{~dB}$ band width $(\mathrm{GHz})$ & Filler loading (wt \%) \\
\hline A1 (10:1) & $10.40-11.20$ & 4 & -11.50 & 0.80 & 5 \\
\hline A3 (30:1) & $13.12-18.00$ & 3 & -19.27 & 4.88 & 5 \\
\hline
\end{tabular}

TABLE 2 | Reported MA properties of typical rGO-based hybrids in the recent literatures.

\begin{tabular}{|c|c|c|c|c|c|}
\hline Absorber & Loading (wt \%) & $R L_{\min }(\mathrm{dB})$ & Bandwidth (GHz) & Thickness (mm) & References \\
\hline Porous Cocoon-like rGO & 7 & -29.05 & 5.27 & 2.00 & Shah et al., 2015 \\
\hline $\mathrm{CeO}_{2}-\mathrm{rGO}$ & 50 & -45.90 & 4.50 & 2.00 & Wang Z.Q. et al., 2018 \\
\hline $\mathrm{rGO} / \mathrm{MWCNTs} / \mathrm{ZnFe}_{2} \mathrm{O}_{4}$ & 50 & -23.80 & 2.60 & 1.50 & Shu et al., 2018 \\
\hline $\mathrm{MoS}_{2} / \mathrm{rGO}$ & 60 & -67.10 & 5.92 & 1.95 & Quan et al., 2017a \\
\hline $\mathrm{rGO} / \mathrm{Ni}$ & 10 & -39.03 & 4.30 & 2.00 & Xu et al., 2018 \\
\hline $\mathrm{Sn} / \mathrm{rGO}$ & 5 & -39.54 & 5.52 & 5.00 & This study \\
\hline
\end{tabular}

A

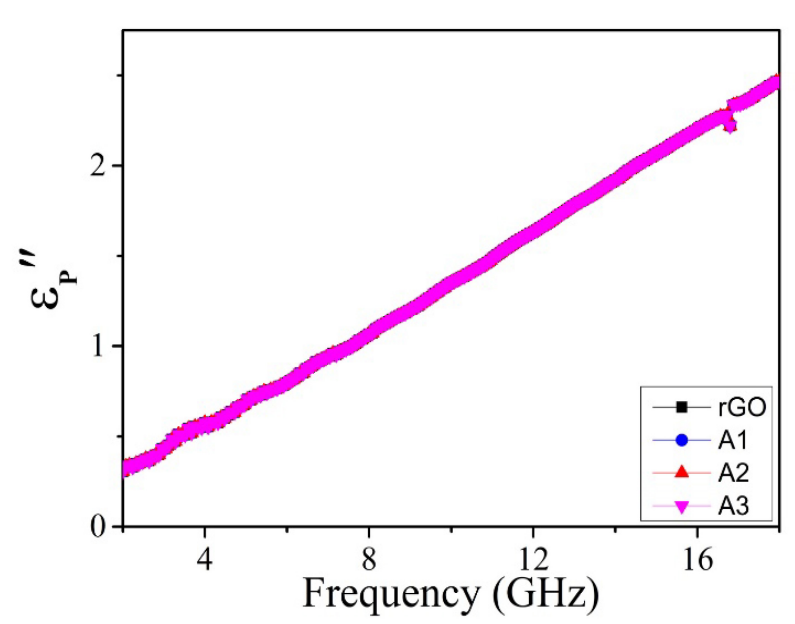

B

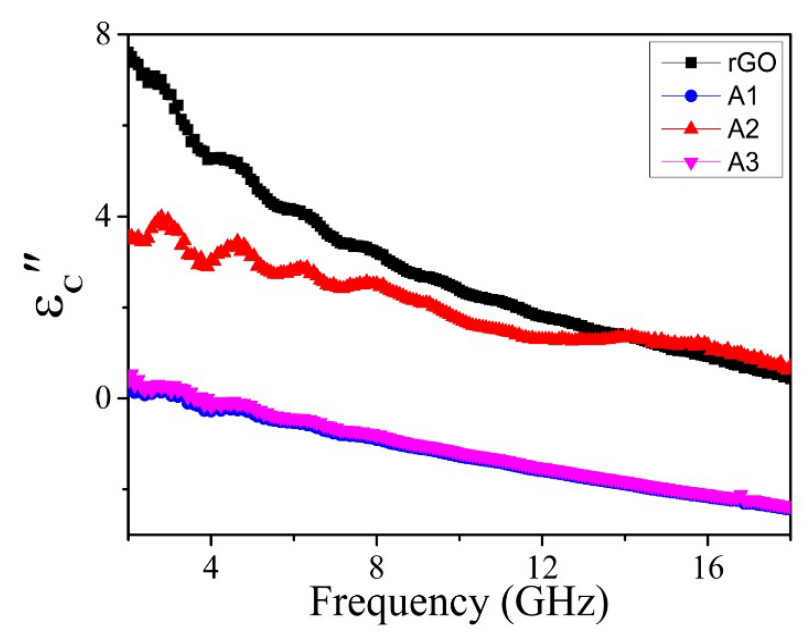

FIGURE 9 | The contributions of polarization (A) $\varepsilon_{p}^{\prime \prime}$ and conductivity (B) $\varepsilon_{C}^{\prime \prime}$ of $r G O, A 1, A 2$, and A3.

bandwidth $(6.24 \mathrm{GHz})$. According to the requirements of thin thickness, lightness, broad effective absorption bandwidth and strong absorption ability for materials, rGO has weak EM wave absorption performance. Therefore, $\mathrm{Sn}$ microspheres were used to regulate impedance matching of the composites in this work. As we can see in Figures $7 \mathbf{B}-\mathbf{D}$, with the increase of $\mathrm{Sn}$ microspheres, the EM wave absorption performance shows a tendency to increase first and then decrease. Among them, A2 has the best performance with the minimum RL $(-39.54 \mathrm{~dB})$, thin thickness of $3 \mathrm{~mm}$, and the broad effective absorption bandwidth $(5.52 \mathrm{GHz})$. Other excellent parameters change less with the improvement of absorbing performance. Compared with A2, A1, and A3 have poor impedance matching and attenuation capability (Figure 8), which means they have weak energy storage and energy dissipation capacity (Figures 6A,B), resulting in poor EM wave absorption performance. The EM wave absorption performance of $\mathrm{rGO}, \mathrm{A} 1, \mathrm{~A} 2$, and $\mathrm{A} 3$ with the same filler loading (Sn/rGO: $5 \mathrm{wt} \%$ ) is summarized in Table 1. In addition, Table 2 summarizes typical rGO-based hybrids (in paraffin) and their corresponding MA properties reported in recent literatures.

In order to understand the loss mechanism and relative factors, the following analysis was done. Two necessary conditions must be satisfied for absorbing material to have excellent absorption performance. On the one hand, good impedance matching means that the incident EM wave enters the material as complete as possible. It can reduce direct reflection on the surface of the material. On the other hand, attenuation characteristics means EM wave can be rapidly attenuated after entering the material. The following equations are used as a representation (Quan et al., 2017b; Zhao et al., 2017):

$$
Z=\frac{Z_{\text {in }}}{Z_{0}}=\sqrt{\mu_{r} / \varepsilon_{r}}
$$


A

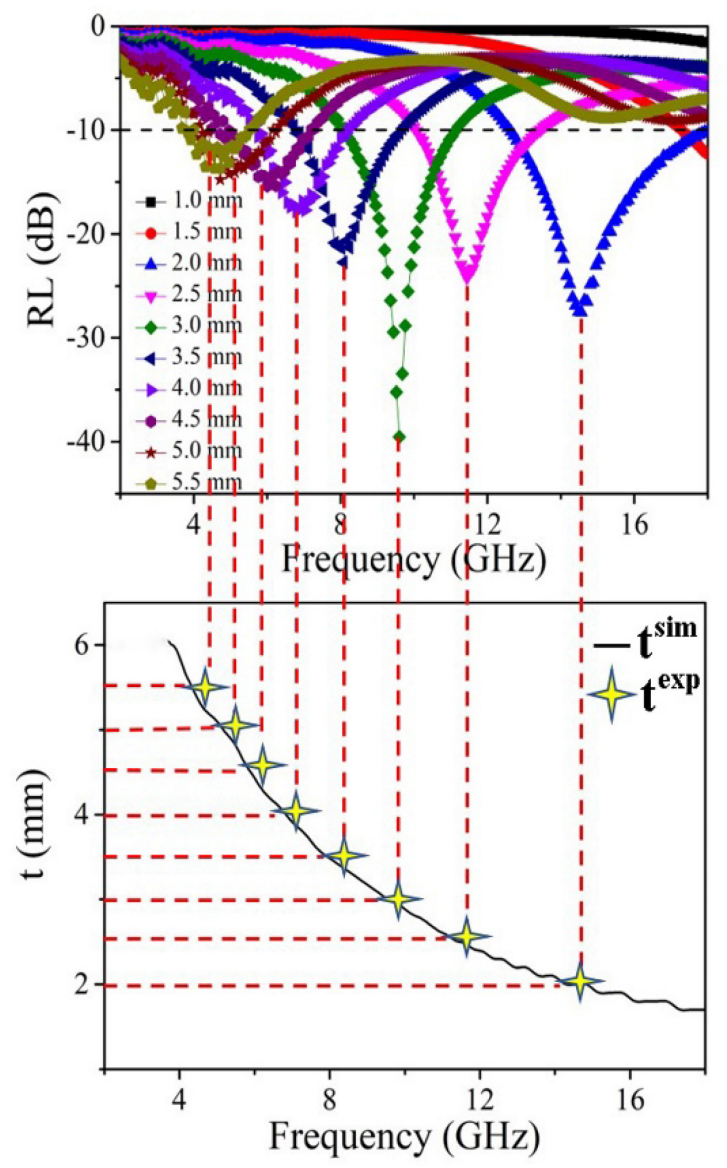

B

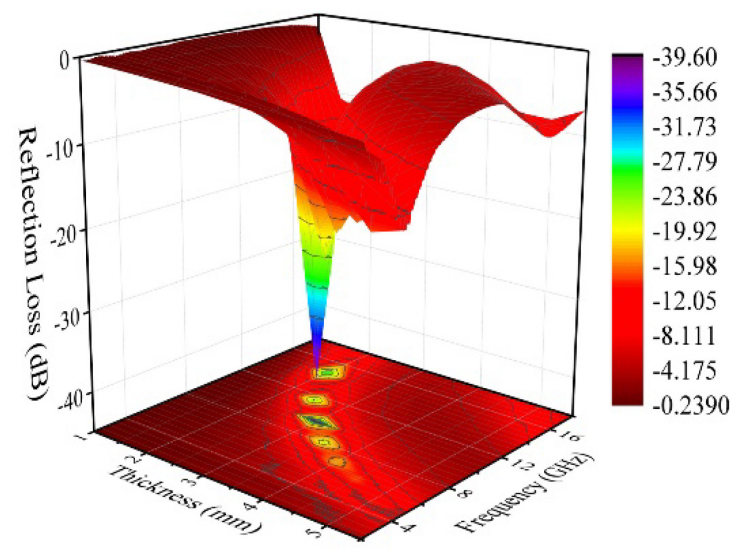

C

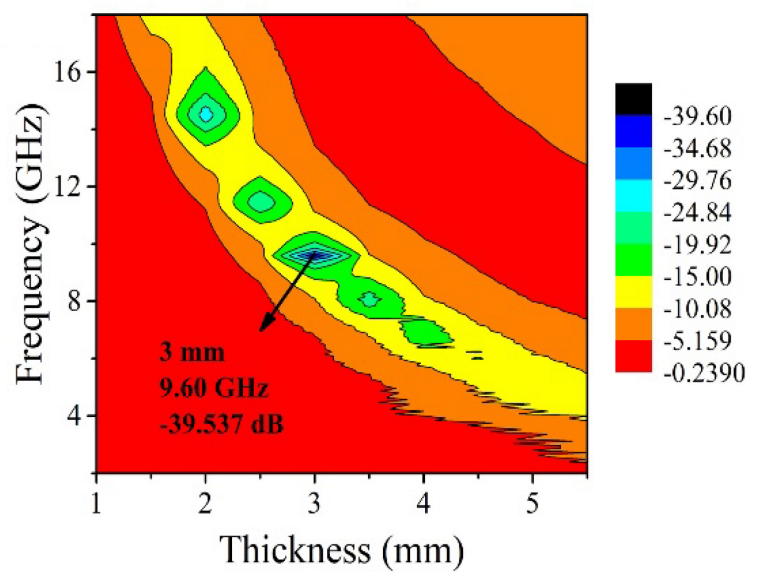

FIGURE 10 | (A) Simulations of the A2 thickness versus peak frequency under the $1 / 4 \lambda$ model, (B) $3 D$ presentation and (C) contour map of reflection loss for A2 with different thicknesses in the frequency range of $2-18 \mathrm{GHz}$.

$$
\alpha=\frac{\sqrt{2} \pi f}{c} \times \sqrt{\left(\mu^{\prime \prime} \varepsilon^{\prime \prime}-\mu^{\prime} \varepsilon^{\prime}\right)+\sqrt{\left(\mu^{\prime \prime} \varepsilon^{\prime \prime}-\mu^{\prime} \varepsilon^{\prime}\right)^{2}+\left(\mu^{\prime \prime} \varepsilon^{\prime}-\mu^{\prime} \varepsilon^{\prime \prime}\right)^{2}}}
$$

Herein, $Z, Z_{0}$, and $\alpha$ are the impedance matching ratio, impedance of free space and attenuation constant, respectively. The best impedance matching is obtained through the value of $Z$, which is $Z=1\left(\mu_{r}\right.$ equals to $\left.\varepsilon_{r}\right)$. The higher the value of $\alpha$, the stronger the ability to consume EM wave. In Figure 8, it can be found that the tendency of the impedance matching ratio is $\mathrm{A} 2>\mathrm{rGO}>\mathrm{A} 3>\mathrm{A} 1$ (Figure 8A) and the trend of the attenuation constant is $\mathrm{rGO}>\mathrm{A} 2>\mathrm{A} 3>\mathrm{A} 1$ (Figure 8B). Although rGO has the maximum attenuation coefficient, its impedance matching is poor, which means less EM wave can get into the material, resulting in higher RL value. According to the equations above, A2 shows the best EM wave absorbing property due to the best impedance matching and relatively large attenuation constant.

For non-magnetic materials, the value of $\varepsilon$ " represents its electromagnetic loss capacity. According to the Eq. 2, the $\varepsilon^{\prime \prime}$ is mainly enhanced by the $\sigma$ of the $\mathrm{Sn} / \mathrm{rGO}$ network, polarizations at the $\mathrm{Sn}-\mathrm{rGO}$ and $\mathrm{Sn}$ - Sn interfaces, and the defect-dipoles generated by the oxygen vacancies. The contributions of polarization $\varepsilon_{p}^{\prime \prime}$ and conductivity $\varepsilon_{c}^{\prime \prime}$ for samples have been compared, as shown in Figure 9. It is found that the conductivity loss plays a dominant role for all the samples. rGO has the highest value of conductivity loss, nevertheless, shows low EM wave absorption ability due to the poor impedance matching. A2 has high conductivity loss and proper impedance matching, consequently, demonstrates the excellent EM wave absorption performance (Figure 7). When Sn microspheres are anchored onto the rGO sheets, the mobile holes in the rGO sheets interact with the localized electrons on the Sn microspheres which are caused by oxygen vacancies via coulomb interactions, resulting in hole trapping at the vacancy sites and effective electron transfer. Owing to the presence of charge transfer between the $\mathrm{Sn}$ and $\mathrm{rGO}$, the combined motion of the collective interfacial dipoles could further improve the EM wave absorption performance. And then the introduction of solid conductors increases the conductivity of A2 and provides an optimal conductive network, which maximizes the macroscopic current caused by carriers and facilitates the conversion of electromagnetic energy into heat energy. Whereas with the 


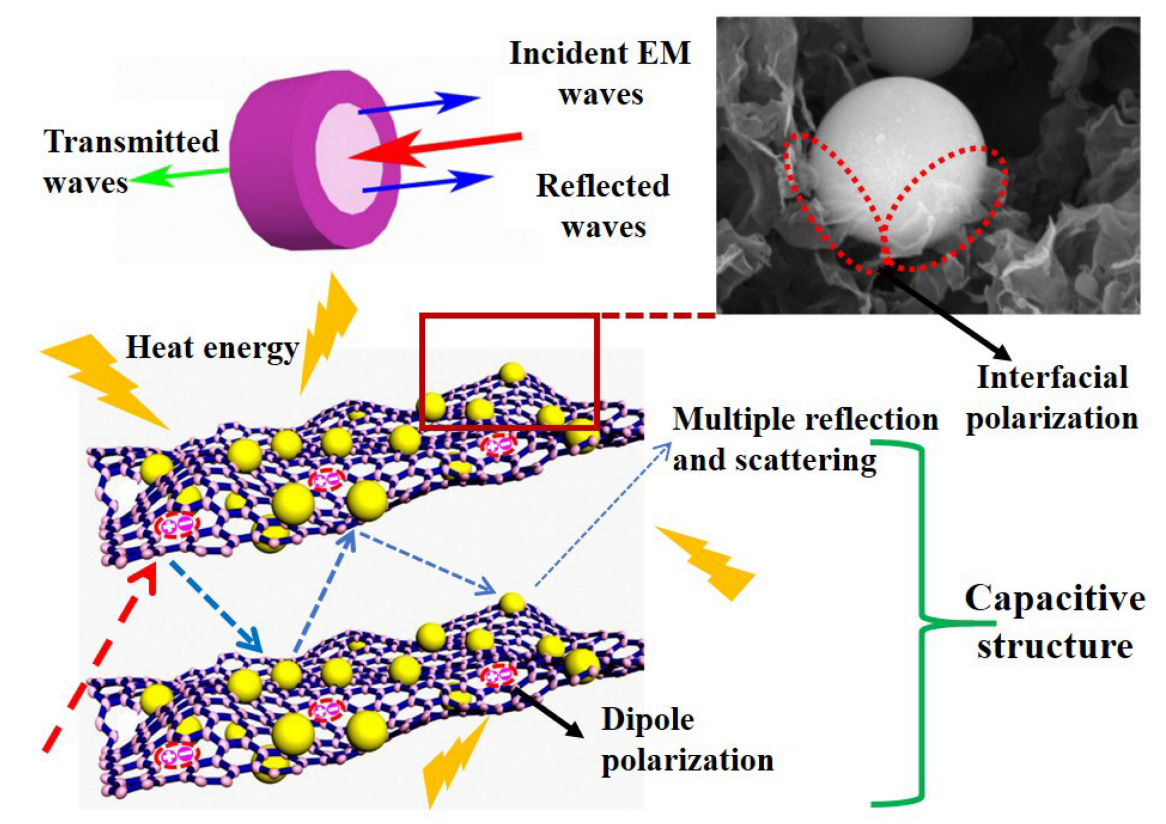

FIGURE 11 | Schematic description of EM wave attenuation mechanism of the A2 hybrids.

increase of $\mathrm{Sn}$, the conductive network is gradually repaired and the vacancy is reduced, which reduces the degree of electron transition and ultimately leads to the reduction of A3 conductivity loss. This provides strong support for the subsequent attenuation mechanism.

It can be seen from Figure 10A that the EM wave absorption performance is sensitive to thickness. As the thickness increases, the $\mathrm{RL}_{\min }$ moves to lower frequency. This can be explained by the quarter wavelength $(\lambda / 4)$ matching mechanism (Shah et al., 2015; Shu et al., 2018). The relationship between thickness and corresponding frequency of absorption peak can be expressed by the equation as follows (Liang et al., 2017):

$$
t_{m}=\frac{n \lambda}{4}=\frac{n c}{4 f_{m} \sqrt{\left|\varepsilon_{r} \mu_{r}\right|}} \quad(n=1,3,5, \ldots)
$$

Herein $t_{m}, f_{m}$, and $\lambda$ are the thickness of the absorber, the peak frequency and the quarter-wavelength at $f_{m}$, respectively. The physical meaning is when the $t_{m}$ and $f_{m}$ satisfy the equation above, the phase difference of the reflected EM wave will be $180^{\circ}$ (the reflected wave comes from the upper and bottom interface). The induced offset effect causes the disappearance of both incident and reflected wave. As shown in Figure 10A, all the $t^{\exp }$ stars fit well with the simulated $t^{\text {sim }}$ curve, conforming that the excellent EM wave absorption performance of A2 can be interpreted by the quarter wavelength matching model. Figure $10 \mathrm{~B}$ depicts the $3 \mathrm{D}$ representation of reflection loss for A2. As we can see, the RL value of the maximum absorption at different frequency can be obtained by controlling the thickness of the EM wave absorber. Figure 10C shows the contour map of reflection loss for A2 with different thicknesses in the frequency range of 2-18 GHz. A2 exhibits the minimum $\mathrm{RL}(-39.54 \mathrm{~dB})$ with a thickness of $3 \mathrm{~mm}$ at $9.60 \mathrm{GHz}$. It can be seen that the absorption band can span $(<-10 \mathrm{~dB})$ almost the whole frequency range ( $4-18 \mathrm{GHz}$ ) by optimizing the thickness. As a consequence, the quarter wavelength matching model is also well consistent with the contour map.

The attenuation mechanism of $\mathrm{Sn} / \mathrm{rGO}$ composites is mostly conduction loss and polarization effect (see Figure 11). The excellent absorption performance is mainly attributed to the balanced impedance match and the unique capacitive structure. Sn has poor electrical conductivity. By forming heterogeneous structure with RGO in a moderate proportion, there is a balance between impedance matching and attenuation constant, which improves the EM wave absorption performance. When EM wave transmits into the material, it causes the directional migration of carriers, leading to oscillating current. Furthermore, the boundary charge leads to dielectric relaxation and polarization. Under the influence of EM field, the EM wave entering the material is repeatedly scattered, and a large number of positive and negative charge areas are formed on the pore wall, which promotes polarization loss and improves the overall absorption capacity. According to Coulomb interaction, the surface of the Sn microsphere has a higher concentration of aerobic vacancy, local electrons are generated on the smooth Sn microspheres and interact with the pores of rGO. As a result, electrons are captured by the holes in vacancy, which leads to effective electron transfer. The interface and defect dipole polarization provide the condition for capacitive structure, adjacent rGO sheets can form a kind of capacitive structure that helps polarize the EM field and reduces the power of the incident EM wave. Finally, the intricate conductive network formed in the composites generates dissipative current, partial conversion energy can be consumed during transmission, resulting in ohmic loss. All kinds of data and theories show that $\mathrm{Sn} / \mathrm{rGO}$ composite is a new kind of absorbing material with high efficiency and good heat resistance prospect (Wen et al., 2013). 


\section{CONCLUSION}

In summary, $\mathrm{Sn} / \mathrm{rGO}$ composites with simple synthesis process and adjustable dielectric parameters was successfully prepared. The obtained dielectric materials possess excellent impedance matching and EM wave attenuation ability by adjusting the dielectric constant. And it also has excellent EM wave absorption performance with low filler loading (sample: $5 \mathrm{wt} \%$ ), the minimum $\mathrm{RL}$ is $-39.54 \mathrm{~dB}$ with $3 \mathrm{~mm}$ thickness at $9.60 \mathrm{GHz}$ (effective absorption bandwidth: $5.52 \mathrm{GHz}$ ). The unique structure and conductive network are important for enhancing the EM wave absorption properties. The present study demonstrates that $\mathrm{Sn} / \mathrm{rGO}$ composites have great potential in EM wave absorption field.

\section{DATA AVAILABILITY STATEMENT}

All datasets generated for this study are included in the article/supplementary material.

\section{REFERENCES}

Al-Ghamdi, A. A., Al-Hartomy, O. A., A-Solamy, F. R., Dishovsky, N., Malinova, P., and Atanasova, P. (2016). Conductive carbon black/magnetite hybrid fillers in microwave absorbing composites based on natural rubber. Compos. Part B-Eng. 96, 231-241. doi: 10.1016/j.compositesb.2016.04.039

Batrakov, K., Kuzhir, P., and Maksimenko. (2016). S. Enhanced microwave-toterahertz absorption in graphene. Appl. Phys. Lett. 108:123101.

Cao, M. S., Wang, X. X., Cao, W. Q., Fang, X. Y., Wen, B., and Yuan, J. (2018). Thermally driven transport and relaxation switching self-powered electromagnetic energy conversion. Small. 14, 1800987-1800995.

Chen, H. H., Huang, Z. Y., Huang, Y., Zhang, Y., Ge, Z., Qin, B., et al. (2017). Synergistically assembled MWCNT/graphene foam with highly efficient microwave absorption in both $\mathrm{C}$ and $\mathrm{X}$ bands. Carbon 124, 506-514. doi: 10.1016/j.carbon.2017.09.007

Feng, J., Pu, F. Z., Li, Z. X., Li, X. H., Hu, X. Y., and Bai, J. T. (2016). Interfacial interactions and synergistic effect of CoNi nanocrystals and nitrogen-doped graphene in a composite microwave absorber. Carbon 104, 214-225. doi: 10. 1016/j.carbon.2016.04.006

Feng, W. (2016). Reduced graphene oxide decorated with in-situ growing $\mathrm{ZnO}$ nanocrystals: facile synthesis and enhanced microwave absorption properties. Carbon 108, 52-60. doi: 10.1016/j.carbon.2016.06.084

Guan, B. Y., Yu, X. Y., Wu, H. B., and Lou, X. W. (2017). Complex nanostructures from materials based on metal-organic frameworks for electrochemical energy storage and conversion. Adv. Mater. 29, 1703614-1703634.

$\mathrm{Hu}$, J., Shen, Y., and Xu, L. H. (2019). Synthesis of urchin-like MnO2/reduced graphene oxide (RGO) composite and their wave-absorbing property. Mater. Res. Express 6, 1-9.

Hu, J. T., Zhao, T. K., Peng, X. R., Yang, W. B., Ji, X. L., and Li, T. H. (2018). Growth of coiled amorphous carbon nanotube array forest and its electromagnetic wave absorbing properties. Compos. Part B-Eng. 134, 91-97. doi: 10.1016/j. compositesb.2017.09.071

Huang, T. Y., He, M., Zhou, Y. M., Pan, W. L., Li, S. W., Ding, B. B., et al. (2017). Fabrication and microwave absorption of multiwalled carbon nanotubes anchored with CoS nanoplates. J. Mater. Sci. Mater. Electron. 28, 7622-7632. doi: 10.1007/s10854-017-6455-z

Liang, X. H., Quan, B., Ji, G. B., Liu, W., Zhao, H. Q., Dai, S. S., et al. (2017). Tunable dielectric performance derived from the metal-organic framework/reduced graphene oxide hybrid with broadband absorption. ACS Sustain. Chem. Eng. 5, 10570-10579. doi: 10.1021/acssuschemeng.7b02565

\section{AUTHOR CONTRIBUTIONS}

TL did the experiment and processed the experimental data to writing the manuscript. $\mathrm{LX}, \mathrm{XH}, \mathrm{TZ}, \mathrm{BZ}$, and $\mathrm{GW}$ are responsible for reviewing the manuscript and putting forward suggestions for revision. JD and XT assisted with the experiment.

\section{FUNDING}

This work was supported by the National Natural Science Foundation of China (Grant Nos. 51621091, 51872058, 51772060, and 51972078), Key Laboratory of Advanced Structural-Functional Integration Materials \& Green Manufacturing Technology, Harbin Institute of Technology, Harbin, 150001, China.

\section{ACKNOWLEDGMENTS}

The authors would like to appreciate the financial support for the above funding and the contributions of each author.

Jia, Z. R., Lan, D., Lin, K. J., Qin, M., and Kou, K. C. (2018). Progress in lowfrequency microwave absorbing materials. J. Mater. Sci. Mater. Electron. 29, 17122-17136. doi: 10.1007/s10854-018-9909-z

Kumar, S., Ojha, A. K., Patrice, D., Yadav, B. S., and Materny, A. (2016). One-step in situ synthesis of $\mathrm{CeO} 2$ nanoparticles grown on reduced graphene oxide as an excellent fluorescent and photocatalyst material under sunlight irradiation. Phys. Chem. Chem. Phys. 18, 11157-11167. doi: 10.1039/c5cp04457j

Li, J. S., Hsu, T. C., Hwang, C. C., Lu, K. T., and Yeh, T. F. (2018). Preparation and characterization of microwave absorbing composite materials with GSs or FeCo/GS composites. Mater. Res. Bull. 107, 218-224. doi: 10.1016/j. materresbull.2018.07.028

Li, Z. X., Li, X. H., Zong, Y., Tan, G. G., Sun, Y., Lan, Y. Y., et al. (2017). Solvothermal synthesis of nitrogen-doped graphene decorated by superparamagnetic $\mathrm{Fe} 3 \mathrm{O} 4$ nanoparticles and their applications as enhanced synergistic microwave absorbers. Carbon 115, 493-502. doi: 10.1016/j.carbon. 2017.01.036

Liang, X. H., Liu, W., Cheng, Y., Lv, J., Dai, S. S., Tang, D. M., et al. (2018) Review: Recent process in the design of carbon-based nanostructures with optimized electromagnetic properties. J. Alloys Compd. 749, 887-899. doi: 10. 1016/j.jallcom.2018.03.344

Liang, X. H., Zhang, X. M., Liu, W., Tang, D. M., Zhang, B. S., and Ji, G. B. (2016). A simple hydrothermal process to grow MoS2 nanosheets with excellent dielectric loss and microwave absorption performance. J. Mater. Chem. C 4, 6816-6821. doi: 10.1039/c6tc02006b

Lin, L., Xing, H. L., Shu, R. W., Wang, L., Ji, X. L., Tan, D. X., et al. (2015). Preparation and microwave absorption properties of multi-walled carbon nanotubes decorated with Ni-doped SnO2 nanocrystals. RSC Adv. 5, 9453994550. doi: 10.1039/c5ra17303e

Liu, J., Duan, Y. P., Song, L. L., and Zhang, X. F. (2018). Constructing sandwichlike polyaniline/graphene oxide composites with tunable conjugation length toward enhanced microwave absorption. Organ. Electron. 63, 175-183. doi: 10.1016/j.orgel.2018.09.017

Liu, P., Yan, J., Gao, X., Huang, Y., and Zhang, Y. (2018). Construction of layer-by-layer sandwiched graphene/polyaniline nanorods/carbon nanotubes heterostructures for high performance supercapacitors. Electrochim. Acta. 272, 77-87. doi: 10.1016/j.electacta.2018.03.198

Liu, P., Huang, Y., Yan, J., Yang, Y., and Zhao, Y. (2016). Construction of CuS nanoflakes vertically aligned on magnetically decorated graphene and their enhanced microwave absorption properties. ACS Appl. Mater. Interfaces. 8, 5536-5546. doi: 10.1021/acsami.5b10511 
Liu, T., Xie, X., Pang, Y., and Kobayashi, S. (2016). Co/C nanoparticles with low graphitization degree: a high performance microwave-absorbing material. J. Mater. Chem. C. 4, 1727-1735. doi: 10.1039/c5tc03874j

Liu, P., Huang, Y., Yan, J., and Zhao, Y. (2016). Magnetic graphene@ PANI@ porous $\mathrm{TiO} 2$ ternary composites for high-performance electromagnetic wave absorption. J. Mater. Chem. C 4, 6362-6370. doi: 10.1039/c6tc01718e

Liu, P. B., Gao, S., Wang, Y., Huang, Y., and Luo, J. H. (2020). Carbon nanocages with $\mathrm{N}$-doped carbon inner shell and $\mathrm{Co} / \mathrm{N}$-doped carbon outer shell as electromagnetic wave absorption material. Chem. Eng. J. 381:122653. doi: 10. 1016/j.cej.2019.122653

Lu, S., Xia, L., Xu, J. M., Ding, C. H., Li, T. T., Yang, H., et al. (2019). A permittivityregulating strategy enabling superior electromagnetic wave absorption of lithium-aluminum-silicate (LAS)/rGO nanocomposite. ACS Appl. Mater. Interf. 11, 18626-18636. doi: 10.1021/acsami.9b00348

Lu, S. R., Xia, L., Xu, J. M., Ding, C. H., Li, T. T., Yang, H., et al. (2019). Permittivityregulating strategy enabling superior electromagnetic wave absorption of lithium aluminum silicate/rGO nanocomposites. ACS Appl. Mater. Interfaces 11, 18626-18636. doi: 10.1021/acsami.9b00348

Makarova, T. L., Geydt, P., Zakharchuk, I., Lahderanta, E., Komlev, A. A., and Zyrianova, A. A. (2016). Correlation between manufacturing processes and anisotropic magnetic and electromagnetic properties of carbon nanotube/polystyrene composites. Compos. Part B-Eng. 91, 505-512. doi: 10.1016/j.compositesb.2016.01.040

Meng, F. B., Wang, H. G., Huang, F., Guo, Y. F., Wang, Z. Y., Hui, D., et al. (2018). Graphene-based microwave absorbing composites: a review and prospective. Compos. Part B 137, 260-277. doi: 10.1016/j.compositesb.2017.11.023

Oraizi, H., Abdolali, A., and Fallah, M. (2016). Ultra wide band radar cross section reduction of a perfectly electric conductor sphere by the application of multilayer metamaterial coatings. J. Micro. Optoelectron. Electron. Appl. 15, 457-476. doi: 10.1590/2179-10742016v15i4587

Pang, H., Pang, W. H., Zhang, B., and Ren, N. (2018). Excellent microwave absorption properties of the h-BN-GO-Fe3O4 ternary composite. J. Mater. Chem. C 6, 11722-11730. doi: 10.1039/c8tc03582b

Qu, B., Zhu, C. L., Li, C. Y., Zhang, X. T., and Chen, Y. J. (2016). Coupling Hollow Fe3O4-Fe nanoparticles with graphene sheets for high-performance electromagnetic wave absorbing material. ACS Appl. Mater. Interfaces 8, 37303735. doi: 10.1021/acsami.5b12789

Quan, B., Liang, X.-H., Xu, G.-Y., Cheng, Y., Zhang, Y.-N., Liu, W., et al. (2017a). A permittivity regulating strategy to achieve high-performance electromagnetic wave absorbers with compatibility of impedance matching and energy conservation. New J. Chem. 41, 1259-1266. doi: 10.1039/c6nj03052a

Quan, B., Xu, G. Y., Li, D. R., Liu, W., Ji, G. B., and Du, Y. W. (2017b). Incorporation of dielectric constituents to construct ternary heterojunction structures for high-efficiency electromagnetic response. J. Colloid Interf. Sci. 498, 161-169. doi: 10.1016/j.jcis.2017.03.049

Ren, Y. L., Zhu, C. L., Zhang, S., Li, C. Y., Chen, Y. J., Gao, P., et al. (2013). Threedimensional SiO2@Fe3O4 core/shell nanorod array/graphene architecture: synthesis and electromagnetic absorption property. Nanoscale 5, 12296-12303.

Samadi, A., Hosseini, S. M., and Mohseni, M. (2018). Investigation of the electromagnetic microwaves absorption and piezoelectric properties of electrospun Fe3O4-GO/PVDF hybrid nanocomposites. Org. Electron. 59, 149155. doi: 10.1016/j.orgel.2018.04.037

Shah, A., Wang, Y. H., Huang, H., Zhang, L., Wang, D. X., Zhou, L., et al. (2015). Microwave absorption and flexural properties of Fe nanoparticle/carbon fiber/ epoxy resin composite plates. Compos. Struct. 131, 1132-1141. doi: 10.1016/j. compstruct.2015.05.054

Shu, R. W., Li, W. J., Zhou, X., Tian, D. D., Zhang, G. Y., Gan, Y., et al. (2018). Facile preparation and microwave absorption properties of RGO/ MWCNTs/ZnFe2O4 hybrid nanocomposites. J. Alloys Compd.. 743, 163-174. doi: $10.1016 /$ j.jallcom.2018.02.016

Smitha, P., Singh, I., Najim, M., Panwar, R., Singh, D., Agarwala, V., et al. (2016). Development of thin broad band radar absorbing materials using nanostructured spinel ferrites. J. Mater. Sci. Mater. Electron. 27, 7731-7737. doi: 10.1007/s10854-016-4760-6

Song, C. Q., Yin, X. W., Han, M. K., Li, X. L., Hou, Z. X., Zhang, L. T., et al. (2017). Three-dimensional reduced graphene oxide foam modified with $\mathrm{ZnO}$ nanowires for enhanced microwave absorption properties. Carbon 116, 50-58. doi: 10.1016/j.carbon.2017.01.077
Song, L., Duan, Y., Zhang, Y., and Wang, T. (2017). Promoting defect formation and microwave loss properties in $\delta-\mathrm{MnO} 2$ via Co doping: a first-principles study. Comput. Mater. Sci. 138, 288-294. doi: 10.1016/j.commatsci.2017.06.020

Sun, H., Che, R. C., You, X., Jiang, Y. S., Yang, Z. B., Deng, J., et al. (2014). Cross-stacking aligned carbon-nanotube films to tune microwave absorption frequencies and increase absorption intensities. Adv. Mater. 26, 8120-8125. doi: 10.1002/adma.201403735

Tian, X., Meng, F. B., Meng, F. C., Chen, X. N., Guo, Y. F., and Wang, Y. (2017). Synergistic enhancement of microwave absorption using hybridized polyaniline@helical CNTs with dual chirality. ACS Appl Mater Interfaces 9, 15711-15718. doi: 10.1021/acsami.7b02607

Wang, S. S., Zhao, Y., Gao, M. M., Xue, H. L., Xu, Y. C., Feng, C. H., et al. (2018). Green synthesis of porous cocoon-like rGO for enhanced microwaveabsorbing performances. ACS Appl. Mater. Interfaces 10, 42865-42874. doi: 10.1021/acsami.8b15416

Wang, Z. Q., Zhao, P. F., He, D. N., Cheng, Y., Liao, L. S., Li, S. D., et al. (2018). Cerium oxide immobilized reduced graphene oxide hybrids with excellent microwave absorbing performance. Phys. Chem. Chem. Phys. 20, 14155-14165. doi: $10.1039 / \mathrm{c} 8 \mathrm{cp} 00160 \mathrm{j}$

Wei, Y., Liu, H. J., Liu, S. C., Zhang, M. M., and Gong, C. H. (2018a). Waste cottonderived magnetic porous carbon for high-efficiency microwave absorption. Compos. Commun. 9, 70-75. doi: 10.1016/j.coco.2018.06.007

Wei, Y., Zhang, L., Gong, C. H., Liu, S. C., and Zhang, J. W. (2018b). Fabrication of TiN/Carbon nanofibers by electrospinning and their electromagnetic wave absorption properties. J. Alloys Compd.. 735, 1488-1493. doi: 10.1016/j.jallcom. 2017.11.295

Wen, B., Cao, M. S., Hou, Z. L., Song, W. L., Zhang, L., Lu, M. M., et al. (2013). Temperature dependent microwave attenuation behavior for carbonnanotube/silica composites. Carbon 65, 124-139. doi: 10.1016/j.carbon.2013.07. 110

Wu, F., Sun, M., Chen, C., Zhou, T., Xia, Y., Xie, A., et al. (2019). Controllable coating of polypyrrole on silicon carbide nanowires as a core-shell nanostructure: a facile method to enhance attenuation characteristics against electromagnetic radiation. ACS Sustain. Chem. Eng. 7, 2100-2106. doi: 10.1021/ acssuschemeng.8b04676

Wu, F., Xia, Y. L., Sun, M., and Xie, A. (2018). Two-dimensional (2D) fewlayers WS2 nanosheets: an ideal nanomaterials with tunable electromagnetic absorption performance. Appl. Phys. Lett. 113:052906. doi: 10.1063/1.5040274

Wu, G., Cheng, Y., Yang, Z., Jia, Z., Wu, H., Yang, L., et al. (2018). Design of carbon sphere/magnetic quantum dots with tunable phase compositions and boost dielectric loss behavior. Chem. Eng. J. 333, 519-528. doi: 10.1016/j.cej. 2017.09.174

Xia, L., Yang, Y. N., Zhang, X. Y., Zhang, J., Zhong, B., Zhang, T., et al. (2018). Crystal structure and wave-transparent properties of lithium aluminum silicate glass-ceramics. Ceram. Int. 44, 14896-14900. doi: 10.1016/j.ceramint.2018.04. 202

Xie, A., Zhang, K., Sun, M. X., Xia, Y. L., and Wu, F. (2018). Facile growth of coaxial Ag@polypyrrole nanowires for highly tunable electromagnetic waves absorption. Mater. Design 154, 192-202. doi: 10.1016/j.matdes.2018.05.039

Xu, J., Zhang, X., Yuan, H. R., Zhang, S., Zhu, C. L., Zhang, X. T., et al. (2020). Ndoped reduced graphene oxide aerogels containing pod-like $\mathrm{N}$-doped carbon nanotubes and FeNi nanoparticles for electromagnetic wave absorption. Carbon 159, 357-365. doi: 10.1016/j.carbon.2019.12.020

Xu, W., Wang, G.-S., and Yin, P.-G. (2018). Designed fabrication of reduced graphene oxides/Ni hybrids for effective electromagnetic absorption and shielding. Carbon 139, 759-767. doi: 10.1016/j.carbon.2018.07.044

Xu, X., Shi, W., Li, P., Ye, S., Ye, C., Ye, H., et al. (2017). Facile fabrication of three- dimensional graphene and metal-organic framework composites and their derivatives for flexible all-solid-state supercapacitors. Chem. Mater. 29, 6058-6065. doi: 10.1021/acs.chemmater.7b01947

Yan, F., Guo, D., Zhang, S., Li, C. Y., Zhu, C. L., Zhang, X. T., et al. (2018). An ultra-small NiFe2O4 hollow particle/graphene hybrid: fabrication and electromagnetic wave absorption property. Nanoscale 10, 2697-2703. doi: 10. $1039 / \mathrm{c} 7 \mathrm{nr} 08305 \mathrm{j}$

Yang, Y. N., Xia, L., Zhang, T., Shi, B., Huang, L. N., Zhong, B., et al. (2018). Fe3O4@LAS/RGO composites with a multiple transmission-absorption mechanism and enhanced electromagnetic wave absorption performance. Chem. Eng. J. 352, 510-518. doi: 10.1016/j.cej.2018.07.064 
Zhang, C., Wang, B., Xiang, J., Su, C., Mu, C., Wen, F., et al. (2017). Microwave absorption properties of CoS2 nanocrystals embedded into reduced graphene oxide. ACS Appl. Mater. Interfaces 9, 28868-28875. doi: 10.1021/acsami. $7 \mathrm{~b} 06982$

Zhang, N., Huang, Y., Zong, M., Ding, X., Li, S. P., and Wang, M. Y. (2017). Synthesis of $\mathrm{ZnS}$ quantum dots and $\mathrm{CoFe} 2 \mathrm{O} 4$ nanoparticles co-loaded with graphene nanosheets as an efficient broad band EM wave absorber. Chem. Eng. J. 308, 214-221. doi: 10.1016/j.cej.2016.09.065

Zhang, H., Hong, M., Chen, P., Xie, A. J., and Shen, Y. H. (2016). 3D and ternary rGO/MCNTs/ Fe3O4 composite hydrogels: synthesis, characterization and their electromagnetic wave absorption properties. J. Alloys Compd. 665, 381-387. doi: 10.1016/j.jallcom.2016.01.091

Zhang, L., Liu, W., Shi, W., Xu, X., Mao, J., Li, P., et al. (2018). Boosting lithium storage properties of MOF derivatives through a wet-spinning assembled fiber strategy. Chem. - Eur. J. 24, 13792-13799. doi: 10.1002/chem.201802826

Zhang, N., Huang, Y., and Wang, M. (2018). 3D ferromagnetic graphene nanocomposites with $\mathrm{ZnO}$ nanorods and $\mathrm{Fe} 3 \mathrm{O} 4$ nanoparticles co-decorated for efficient electromagnetic wave absorption Compos. Part B. 136, 135-142. doi: 10.1016/j.compositesb.2017.10.029

Zhang, L., Zhang, X. H., Zhang, G. J., Zhang, Z., Liu, S., Li, P. F., et al. (2015) Investigation on the optimization, design and microwave absorption properties of reduced graphene oxide/tetrapod-like $\mathrm{ZnO}$ composites. RSC Adv. 5, 1019710203. doi: 10.1039/c4ra12591f

Zhang, X., Xu, J., Liu, X. Y., Zhang, S., Yuan, H. R., Zhu, C. L., et al. (2019a). Metal organic framework-derived three-dimensional graphene supported nitrogendoped carbon nanotube spheres for electromagnetic wave absorption with ultralow filler mass loading. Carbon 155, 233-242. doi: 10.1016/j.carbon.2019. 08.074

Zhang, X. C., Xu, J., Yuan, H. R., Zhang, S., Ouyang, Q. Y., Zhu, C. L., et al. (2019b). Large-scale synthesis of three-dimensional reduced graphene oxide/nitrogen-doped carbon nanotube heteronanostructures as highly efficient electromagnetic wave absorbing materials. ACS Appl. Mater. Interfaces 11, 39100-39108. doi: 10.1021/acsami.9b13751

Zhang, X., Zhang, X. C., Wang, D. T., Yuan, H. R., Zhang, S., Zhu, C. L., et al. (2019c). Three dimensional graphene-supported nitrogen-doped carbon nanotube architectures for attenuation of electromagnetic energy. J. Mater. Chem. C. 7, 11868-11878. doi: 10.1039/c9tc04191e

Zhang, X. C., Zhang, X., Yuan, H. R., Li, K. Y., Ouyang, Q. Y., Zhu, C. L., et al. (2020). CoNi nanoparticles encapsulated by nitrogen-doped carbon nanotube arrays on reduced graphene oxide sheets for electromagnetic wave absorption. Chem. Eng. J. 383, 123208-123217.

Zhao, B., Liu, J. W., Guo, X. Q., Zhao, W. Y., Liang, L. Y., Ma, C., et al. (2017). Hierarchical porous Ni@boehmite/nickel aluminum oxide flakes with enhanced microwave absorption ability. Phys. Chem. Chem. Phys. 19, 9128 9136. doi: 10.1039/c7cp00629b

Zhao, X. C., Zhang, Z. M., Wang, L. Y., Xi, K., Cao, Q. Q., Wang, D. H., et al. (2013). Excellent microwave absorption property of Graphene-coated Fe nanocomposites. Sci. Rep. 3, 3421-3425.

Conflict of Interest: The authors declare that the research was conducted in the absence of any commercial or financial relationships that could be construed as a potential conflict of interest.

Copyright (C) $2020 \mathrm{Li}$, Xia, Zhang, Zhong, Dai, Tian, Huang and Wen. This is an open-access article distributed under the terms of the Creative Commons Attribution License (CC BY). The use, distribution or reproduction in other forums is permitted, provided the original author(s) and the copyright owner(s) are credited and that the original publication in this journal is cited, in accordance with accepted academic practice. No use, distribution or reproduction is permitted which does not comply with these terms. 